\title{
The PTEN stabilizer
}

PTEN
signalling
in $\mathrm{T}_{\text {Reg }}$ cells
suppresses the
spontaneous
development
of a lympho-
proliferative
disease
through the regulation of $\mathrm{PI} 3 \mathrm{~K}$ and
mammalian target of rapamycin

Forkhead box P3-positive (FOXP3 $\left.{ }^{+}\right)$ regulatory $\mathrm{T}\left(\mathrm{T}_{\mathrm{Reg}}\right)$ cells maintain immune tolerance and thus, defining the mechanisms that control $\mathrm{T}_{\text {Reg }}$ cell function and stability is crucial for understanding how the immune system is regulated. Previous studies have implicated the negative regulator of phosphoinosi-

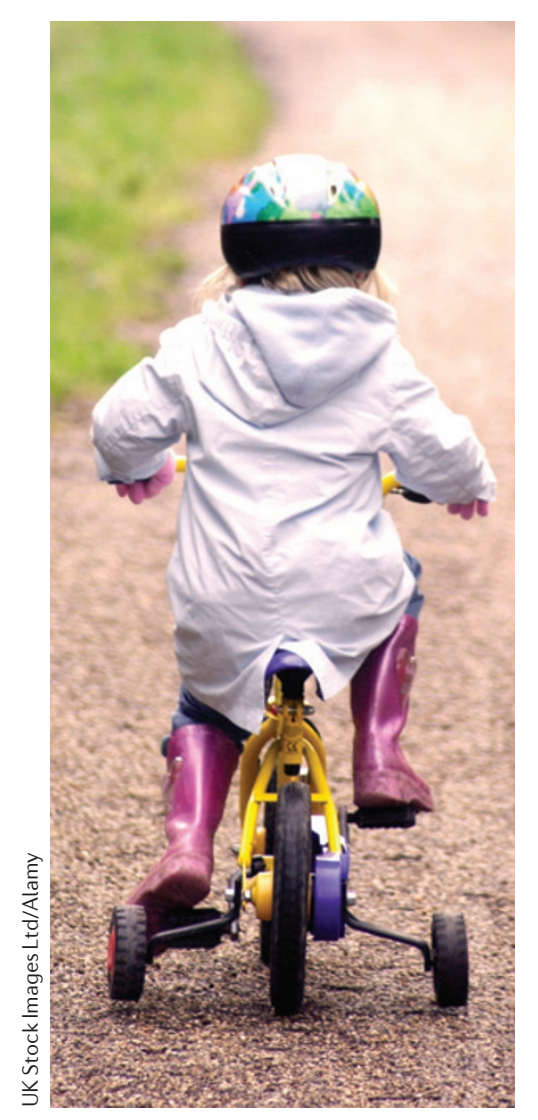
phosphatase PTEN, which is the main tide 3-kinase (PI3K), in $\mathrm{T}_{\text {Reg }}$ cell activation. Now, two studies published in Nature Immunology show that PTEN,
(mTOR) complex 2 (mTORC2), is crucial for maintaining $\mathrm{T}_{\mathrm{Reg}}$ cell homeostasis, function and stability.

Using similar techniques, both groups generated mice in which $\mathrm{T}_{\text {Reg }}$ cells specifically lacked Pten (Pten ${ }^{\mathrm{f} / \mathrm{fl}}$ Foxp3-Cre mice). Over time, these mice developed an autoimmune and lymphoproliferative disease with renal pathology. Further analysis of these mice showed an accumulation of germinal centre B cells, high levels of serum autoantibodies and high number of T cells with an activated or memory phenotype. $\mathrm{T}$ cells from these mice expressed high levels of interferon- $\gamma$ (IFN $\gamma$ ) and CXC-chemokine receptor 3 , which are both signatures of T helper $1\left(\mathrm{~T}_{\mathrm{H}} 1\right)$ cells. In addition, high numbers of follicular helper $\mathrm{T}$ cells $\left(\mathrm{T}_{\mathrm{FH}}\right.$ cells) were observed in Pten $^{\mathrm{f} / \mathrm{fl}}$ Foxp3-Cre mice compared with control mice. Shrestha et al. showed that the increased $\mathrm{T}_{\mathrm{FH}}$ cell, germinal centre and autoimmune responses were dependent on the increased production of IFN $\gamma$ in $\mathrm{Pten}^{\mathrm{f} / \mathrm{fl}} \mathrm{Foxp3-Cre}$ mice. These data suggest that PTEN signalling in $\mathrm{T}_{\mathrm{Reg}}$ cells suppresses the spontaneous development of a lymphoproliferative disease involving $B$ cells, $T_{H} 1$ cells and $T_{F H}$ cells.

Surprisingly, given the loss of immune tolerance in these mice, high numbers of FOXP3 $3^{+} \mathrm{T}_{\text {Reg }}$ cells, in particular FOXP3 ${ }^{+} \mathrm{CD} 25^{-} \mathrm{T}_{\mathrm{Reg}}^{\mathrm{keg}}$ cells, were observed in Pten ${ }^{\mathrm{f} / \mathrm{l}}$ Foxp3-Cre mice. Huynh et al. provided data to suggest that PTEN-deficient $\mathrm{T}_{\text {Reg }}$ cells might be pathogenic in vivo. Using a lineage-tracing system, both groups found that in addition to a loss of CD25 expression, PTEN-deficient $\mathrm{T}_{\text {Reg }}$ cells lost expression of FOXP3 over time and, as shown by Shrestha et al., these 'ex- $\mathrm{T}_{\mathrm{Reg}}$ cells' upregulated the expression of molecules characteristic of $\mathrm{T}_{\mathrm{H}} 1$ cells and $\mathrm{T}_{\mathrm{FH}}$ cells. These data indicate that PTEN maintains $\mathrm{T}_{\text {Reg }}$ cell stability.

$\mathrm{T}_{\text {Reg }}$ cells from Pten ${ }^{\mathrm{f} / \mathrm{fl}}$ Foxp3-Cre mice were shown by both groups to have increased glycolytic metabolism compared with control $\mathrm{T}_{\text {Reg }}$ cells, which might disrupt $\mathrm{T}_{\mathrm{Reg}}$ cell stability and homeostasis. Loss of PTEN in $\mathrm{T}_{\text {Reg }}$ cells also resulted in increased activation of mTORC2 (but not mTORC1) compared with control cells. Abrogation of mTORC2 activity in PTEN-deficient $\mathrm{T}_{\mathrm{Reg}}$ cells either through deletion of the mTORC2 component Rictor (Shrestha et al.) or through inhibition of AKT (Huynh et al.), which is downstream of mTORC2, restored CD25 expression. As shown by Shrestha et al., abrogation of mTORC2 activity also blocked the spontaneous development of $\mathrm{T}_{\mathrm{H}} 1$ cells, $\mathrm{T}_{\mathrm{FH}}$ cells and germinal centre $B$ cells, as well as renal pathology, in Pten ${ }^{\mathrm{f} / \mathrm{f}}$ Foxp3-Cre mice. Inhibition of $\mathrm{PI} 3 \mathrm{~K}$, which is upstream of mTORC2, also prevented the loss of CD25 and FOXP3 in PTEN-deficient $\mathrm{T}_{\mathrm{Reg}}$ cells in vitro (Huynh et al.).

Thus, the control of PI3K and mTORC2 activity by PTEN maintains $\mathrm{T}_{\text {Reg }}$ cell lineage stability, $\mathrm{T}_{\text {Reg }}$ cellmediated control of effector responses and thus immune homeostasis.

Olive Leavy

ORIGINAL RESEARCH PAPERS Shrestha, S. et al $T_{\text {Reg }}$ cells require the phosphatase PTEN to restrain $\mathrm{T}_{\mathrm{H}} 1$ and $\mathrm{T}_{\mathrm{FH}}$ cell responses. Nature Immunol. http://dx.doi.org/10.1038/ni.3076 (2015) Huynh, A. et al. Control of PI(3) kinase in $\mathrm{T}_{\text {Reg }}$ cells maintains homeostasis and lineage stability. Nature Immunol. http://dx.doi.org/10.1038/ni.3077 (2015) 